\title{
Allgemeine Information
}

\author{
Veranstalter \\ $\nabla$ \\ ÖRG \\ Österreichische Röntgengesellschaft
}

\section{Tagungspräsident}

$\nabla$

Prim.-Doz. Dr. K.H. Hausegger

\section{Kongressbüro}

$\nabla$

Sekretariat OERG 2013

c/o ESR Büro

Neutorgasse 9

1010 Wien

Tel.: +43/1/5320507

Fax: +43/1/5320507448

E-Mail: kongress@oerg.at

\section{Hotelbuchung}

Tourismus Salzburg GmbH

Auerspergstraße 6

5020 Salzburg

Tel.: +43/662/889 87603

Fax: $+43 / 662 / 8898766$

E-Mail: meeting@salzburgcongress.at

\section{Ausstellungsorganisation}

\section{$\nabla$}

MAW

Medizinische Ausstellungs- und

Werbegesellschaft

Freyung 6/3

1010 Wien

Tel.: +43/1/536 6342

Fax: +43/1/535 6016

E-Mail: maw@media.co.at
Tagungsort

\section{$\nabla$}

Salzburg Congress

Auerspergstraße 6

(Eingang: Kurpark/Mirabellgarten)

5020 Salzburg

Tel.: +43/662/889 870

Fax: +43/662/889 87210

E-Mail: info@salzburgcongress.at 